\title{
Editorial
}

\section{Road Traffic Injuries: an Emerging Problem in Bangladesh}

\section{SK Biswas}

Increasing road traffic accidents (RTA) are a major threat to life in many parts of world. According to the 'World Report on Road Traffic Injury Prevention-2004', worldwide an estimated 1.2 million people are killed in traffic accidents each year and as many as 50 million are injured. The majority of these, about 85 per cent, occur in those countries that the World Bank classifies as low or middle income and where vehicle ownership levels are low by western standards and where much investment is being made in improving road infrastructure. Projections indicate that these figures will increase by about $65 \%$ over the next 20 years unless there is new commitment to prevention ${ }^{1}$. Road traffic accidents are a 'global tragedy' with ever-rising trends in fatalities and injuries in the developing countries. All known studies have also shown that, whilst road deaths are slowly decreasing in highincome countries, low income countries face a worsening situation $^{2}$.

The road safety situation in Bangladesh has been deteriorating with increasing number of road accident deaths. According to police report total number of road traffic accidents was 40,927 in Bangladesh during period of 2001-2010, and number of killed person was 32,261. In 2010; 3,300 people were killed in RTAs, which rose to 5928 in 2011 , a rise of $80 \% \%^{3}$. Approximately $33 \%$ of the beds in primary and secondary level hospitals in Bangladesh were occupied by injury-related patients ${ }^{4}$. The estimated cost of road accident is 7500 crore Bangladeshi taka ( $1 \mathrm{USD}=82 \mathrm{BDT})$ per year. This is said to be $1.5 \%$ of $\mathrm{GDP}^{3}$. The social tragedy related to each life lost in road accidents is much more shocking than these reflected numerically by these statistics. A study in Bangladesh found that many households were made destitute by the death or injury of a family member in a road traffic accident. Medical costs, funeral costs and the loss of family income can lead to decreased food consumption, a fall in living standards and increased indebtedness ${ }^{5}$.

According to a study conducted by the Accident Research Center (ARC) of BUET the fatality rate of road accidents in Bangladesh is very high, with about 60 deaths per 10,000 vehicles per year as compared with rates of 2 in USA, 1.4 in UK and 3.3 in New Zealand. Bangladesh has the lowest motorization level, only 2 motor vehicles for 1000 people as compared with 765 motor vehicles in USA, 426 motor vehicles in UK and 560 motor vehicles in New Zealand for 1000 people. Hence, though motor vehicles per 1000 people are lowest but fatalities are highest. In India, numbers of motor vehicles are 12/ 1000 peoples and fatalities rate is 25 per 10,000 vehicles. In Pakistan, numbers of motor vehicles are 13/ 1000 peoples and fatalities rate is 19 per 10,000 vehicles.

There are many causes of increasing road accidents; rapid growth in population, motorization, urbanisation and lack of investment in road safety are the main causes.

Dr. Swapan Kumar Biswas, FCPS (Surgery), MRCS (Edin), Assistant professor, Dept. of Surgery, FMC, Faridpur. Mobile:+8801712120828. Email: Swapan_kb@yahoo.com
Violation of traffic laws by the drivers and pedestrian, unplanned roads and highways, incompetent traffic system, faulty vehicles on road are also the possible explanation of increasing road accident in recent years. Accidents are also taking place in the country almost every day due to the movement of illegal 'Nasimon' and 'Karimon' like vehicles. A study on "Road Traffic Accident by 'Nasimon' and 'Karimon'-A Study in Faridpur Medical College Hospital" by Jahangir ASM, et al revealed $12 \%$ of total RTA victims who attended $\mathrm{FMCH}$ are due to accident of these locally made vehicle 6 .

Road traffic-related crashes impose an enormous public health burden in our country. The costs are huge. The economic consequence from the ambulance that transports an injured person to the emergency room, hospitalization, rehabilitation, earnings loss, and social and family disruption are far-reaching. But these types of injuries are preventable, and lives will be saved and injuries and suffering will be reduced once effective road traffic injury prevention strategies are implemented. The traffic police department has a crucial role to play in identifying and controlling reckless driving, speeding and unstable, illegal, faulty or overloaded vehicles. The maintenance, repair and expansion of roads coupled with setting up dividers on national highways, cautioning signals for hazardous locations, disseminating information on driving and road safety to masses through media and exemplary punishment for violating traffic laws are some of the main areas that need to be worked on rigorously by the government. As citizens, we too have a role to play in ensuring road safety. While travelling in public transports, passengers should protest and stop speeding and reckless driving by bus and taxi drivers. Owners of motor vehicles should ensure that employed drivers have genuine licenses, are properly trained and drive responsibly. Road safety education to pedestrians, especially children, within the communities by community leaders is also a good way to promote road safety.

\section{References}

1. Peden M, Scurfield R, Sleet D, Mohan D, Jyder A, Jarawan E, Mathers C (Eds) (2004). World Report on Road Traffic Injury Prevention. Geneva: World Health Organization.

2. Peden M, Hyder AA. Road traffic injuries are a global public health problem. BMJ 2002; 324:1153-54.

3. Arif A. Lowest motor vehicle but highest road accidents in Bangladesh. Amar Desh. 2012 Jan 14; page 1, column 6.

4. Mashreky SR, Rahman A, Khan TF, Faruque M, Svanstrom L, Rahman F. Hospital burden of road traffic injury: major concern in primary and secondary level hospitals in Bangladesh. Public Health 2010; 124(4):185-9. Epub 2010 Apr 8.

5. Aeron-Thomas A, Jacobs GD, Sexton B, Gururaj G, Rahman F The Involvement and Impact of Road Crashes on the Poor: Bangladesh and India case studies. 2004; http://www.grsproadsafety.org/themes/default/pdfs/The\%20Poor_f inal\%20final\%20report.pdf [accessed 14 January 2012].

6. Chowdhury ASMJ, Alam MS, Biswas SK, Saha RK, Mandol AR, Rahman MM et. al. Road Traffic Accident by 'Nasimon' and 'Karimon'-A Study at Faridpur Medical College Hospital. Faridpur Med Coll J. 2012. 7(1):6-9 